\title{
O setor de máquinas e implementos agrícolas no estado do Rio Grande do Sul: os determinantes de decisões logísticas
}

\author{
Cássia Aparecida Pasqual \\ Eugênio Ávila Pedrozo** \\ Marco Antonio Montoya ${ }^{* * * *}$
}

\section{Resumo}

Com o objetivo de estabelecer padrões de decisões logísticas, foi realizada uma pesquisa de campo, de caráter exploratório e descritivo, num único momento, considerando duas categorias de produtos, em diferentes portes das empresas do setor de máquinas e implementos agrícolas do Noroeste Rio-Grandense. Para isso, por meio de uma avaliação transversal de posicionamento logístico, analisou-se em que medida as características do negócio influenciam nas decisões logísticas e nos tipos de organização do fluxo de produtos. Verificou-se que não existe um padrão homogêneo de decisões logísticas no setor, sendo este diferenciado de acordo com o porte das empresas. Entretanto, concluiu-se que é possível orientar e direcionar o planejamento e a tomada de decisão através da organização do fluxo de produtos, o qual se constitui num quadro conceitual de apoio à tomada de decisão dos gestores do setor analisado.

Palavras-chave: Decisões logísticas. Avaliação transversal. Organização do fluxo de produtos. Setor de máquinas e implementos agrícolas.

* Professora da Faculdade de Ciências Econômicas, Administrativas e Contábeis da Universidade de Passo Fundo (UPF). Mestra em Agronegócios no Programa de Pós-Graduação em Administração - Centro de Estudos e Pesquisas em Agronegócios (Cepan) da Universidade Federal do Rio Grande do Sul (UFRGS). cpasqual@upf.br.

** Professor do PPG-Agronegócios/ Cepan/UFRGS. Professor do PPGA/Escola de Administração/UFRGS. E-mail.

**** Professor da Faculdade de Ciências Econômicas, Administrativas e Contábeis da UPF. Doutor em Economia Aplicada pela Escola Superior de Agricultura Luiz de Queiroz (Esalq/USP). montoya@upf.br. 


\section{Introdução}

Atualmente, a importância atribuída à gestão de estoques vem, de modo gradativo, adquirindo espaço entre as empresas, pois estas têm buscado, cada vez mais, garantir a disponibilidade de seus produtos ao consumidor, com cada vez menos nível de estoque e consequente redução de custos. Assim, para um gerenciamento eficiente da cadeia de suprimentos, deve-se partir desde o fornecedor inicial até o consumidor final, abrangendo a gestão dos fluxos de produtos, de informações e de recursos financeiros.

Para a logística ser considerada um importante fator de vantagem competitiva em cadeias de suprimentos, suas principais decisões devem estar articuladas ao longo do tempo, possibilitando o desenvolvimento de padrões de decisão coerentes com as características do negócio. Em consequência, nos últimos anos, as discussões sobre os processos de produção, posicionamento e as vantagens competitivas que conferem às empresas têm se tornado cada vez mais importante. Como resultado dessas discussões, Porter (1991) sugere que se avalie a estratégia empresarial com base em dois níveis distintos e complementares, denominados "transversal" e "longitudinais". Com isso, possibilita-se definir padrões de decisões que poderão ser usados pelos gestores empresariais como vantagens competitivas (análise transversal) e depois para manter posições competitivas sustentáveis ao longo do tempo (análise longitudinal).

Entre os diferentes setores que fazem parte do conjunto de fornecedores de insumos e bens de capital para os produtores rurais da economia gaúcha e brasileira, a montante do agronegócio, destaca-se o setor de máquinas e implementos agrícolas, por procurar manter-se competitivo diante de uma demanda cada vez mais exigente em termos de inovações tecnológicas (PASQUAL, 2005).

É válido salientar que a mesorregião Noroeste, no estado do Rio Grande do Sul, constitui-se numa das maiores regiões produtoras desse setor e, portanto, num importante fornecedor de bens de capital do agronegócio gaúcho e brasileiro. Segundo o Sindicato de Máquinas Agrícolas do Estado do Rio Grande do Sul (Simers, 2004), o estado detém $62 \%$ da indústria brasileira de máquinas e implementos agrícolas, e a mesorregião aglomera $78 \%$ da indústria sul-rio-grandense e $48 \%$ da indústria nacional.

Dada a relevância do setor, em âmbito nacional e estadual, este trabalho tem por objetivo compreender melhor o nível transversal da logística do setor de máquinas e implementos agrícolas, mais especificamente na mesorregião Noroeste do estado do Rio Grande do Sul, questionando: quais são as características do negócio 
significativamente correlacionadas com as decisões logísticas e com os tipos de organização do fluxo de produtos? Em particular, esta pesquisa procura, na mesorregião selecionada, a partir de uma análise transversal e com base num modelo operacional de avaliação de posicionamento logístico, estabelecer, por um lado, em que medida as características do negócio influenciam nas decisões de coordenação do fluxo de produtos, de alocação dos estoques e as bases para acionamento da fabricação de produtos acabados e, por outro, identificar de que maneira essas características influenciam nos tipos de organização do fluxo de produtos.

Esse tipo de pesquisa justifica-se na medida em que permite avaliar, no setor, a magnitude ou a ordem de grandeza das diferentes características do negócio que poderiam influenciar as decisões logísticas e a organização do fluxo de produtos nas pequenas, médias e grandes empresas do setor. A pesquisa justifica-se, também, pelo fato de permitir determinar, por exemplo, se os produtos de alto custo adicionado normalmente apresentam menores ciclos de vida que os de baixo custo adicionado, uma vez que, na avaliação das características do setor, estas podem estar correlacionadas e reagir entre si. A partir do mapeamento e entendimento dessas relações, é possível delimitar quais serão as circunstâncias típicas e atípicas com que acadêmicos e empresários podem se defrontar na pesquisa e no planejamento da logística.

O trabalho está organizado em quatro seções, incluindo esta introdução. $\mathrm{Na}$ segunda seção, demonstra-se o processo metodológico utilizado para determinar as decisões logísticas e a organização do fluxo de produtos; na terceira seção, expõem-se os resultados das correlações das características do negócio com as decisões logísticas e com os tipos de organização dos fluxos de produtos e, por fim, as principais conclusões.

\section{Referencial teórico e método}

Para avaliar as estratégias integradas de produção e logística no âmbito da cadeia de suprimentos, a partir das características do negócio e de suas relações com as decisões logísticas e com a organização do fluxo de produtos, realizou-se uma pesquisa de campo de caráter exploratório e descritivo, num único momento, considerando duas categorias de produtos, em diferentes portes de empresas (pequenas, médias e grandes) do setor de máquinas e implementos agrícolas. $\mathrm{O}$ trabalho constitui-se de uma análise transversal, com base no modelo operacional de avaliação do posicionamento logístico de Wanke (2003ab).

Cabe esclarecer que o modelo operacional utilizado foi desenvolvido por Wanke (2003b), o qual avaliou, de forma conjunta, cinco categorias de produtos em 26 
empresas de grande porte de setores heterogêneos (químico e petroquímico, alimentício, automotivo, eletroeletrônicos, tecnologia e computação e farmacêutico). Porém, este trabalho se diferencia na medida em que avalia um único setor (máquinas e implementos agrícolas), selecionando duas categorias de produtos (SKU classe A e SKU classe C) em 21 empresas e considerando os diferentes portes (pequeno, médio e grande). Espera-se obter, com isso, resultados mais aderentes e específicos, que identifiquem e caracterizem padrões de decisão de posicionamento logístico no setor estudado, de acordo com o tamanho das empresas e as categorias de produtos.

\subsection{Modelo de avaliação transversal: indicadores das características do negócio}

O nível transversal trata da ligação das características do negócio (por exemplo, produto, operação e demanda) com o padrão de decisões na cadeia/sistema de valor num determinado momento. Esse tipo de avaliação, segundo Wanke (2003), possibilita melhor desempenho em termos de custo total e de nível de serviços, por meio do ajuste fino entre as decisões e as características do negócio. Já o nível longitudinal examina por que certas empresas conseguem desenvolver posições de vantagens competitivas e sustentá-las ao longo do tempo. Porter (1991) enfatiza, ainda, que a avaliação do nível transversal é prioritária, uma vez que, sem uma compreensão específica do que sustenta uma posição desejável, seria muito difícil e complexo lidar de forma analítica com o nível longitudinal.

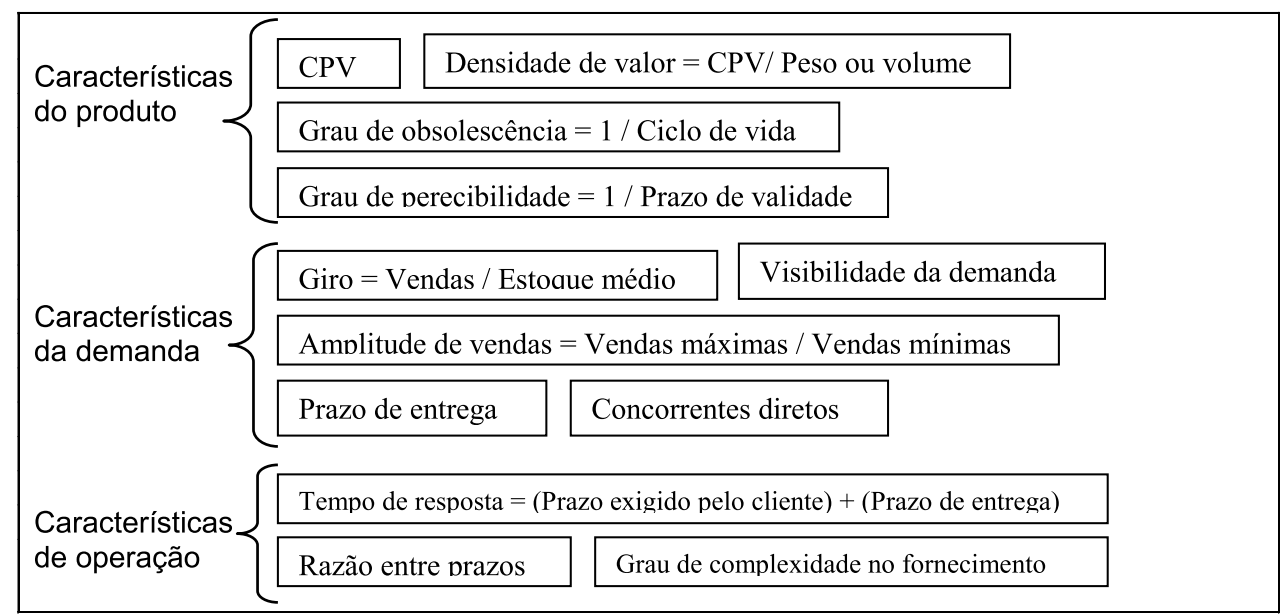

Fonte: elaborado com base em Christopher $(2000,2002)$ e Wanke (2003a).

Figura 1: Indicadores das características do produto, da operação e da demanda 
Com relação à análise transversal da logística integrada como meio para criação de posições competitivas, a literatura focada em operações e serviços registra, de forma dispersa e difusa, que determinados padrões decisórios seriam mais apropriados e/ou seriam verificados com maior frequência para um determinado conjunto de características do produto, da operação e da demanda (WANKE, 2003ab). Para essas características, criaram-se indicadores que permitem a comparação, de modo mais consistente, para estudos dentro desses parâmetros. Christopher (2002) e Wanke (2003a) argumentam que as características do produto englobariam o custo adicionado (custo de produto vendido), a densidade de custos, o grau de obsolescência e o grau de perecibilidade. Características relevantes da operação logística envolveriam o valor do frete, o tempo de resposta e o grau de complexidade no fornecimento. Finalmente, as características da demanda envolveriam a amplitude de vendas, o giro dos estoques e a visibilidade da demanda.

Utilizando esse enfoque da análise transversal, parte-se da hipótese de que as diferentes características do produto, da operação e da demanda constituem-se no meio ambiente determinante dos padrões de decisões logísticas e, consequentemente, da organização do fluxo de produtos. Assim, com o fim de identificar essas características do negócio, a Figura 1 demonstra os indicadores gerados com base nas informações coletadas na pesquisa de campo.

\section{2 Área de abrangência da pesquisa e tamanho da amostra}

A mesorregião Noroeste do Rio Grande do Sul está composta por treze microrregiões, as quais, segundo o IBGE (2004), compreendem um total de $216 \mathrm{mu}$ nicípios, o que perfaz 43,55\% dos municípios do Rio Grande do Sul. Conforme o cadastro do Simers (2004), o estado detém $62 \%$ do setor nacional de máquinas e implementos agrícolas, o que corresponde a um total de 45 empresas (fábricas). O fato de 35 destas estarem localizadas na mesorregião Noroeste confere-lhe uma participação de 77,78\% do estado e $48 \%$ da indústria nacional. Entretanto, para este estudo, algumas empresas desse universo foram descartadas, por serem fabricantes de peças e acessórios utilizados na fabricação do produto acabado, ou seja, por não atenderem o consumidor final, reduzindo-se a amostra para 28 empresas na região. Chegou-se, finalmente, a uma amostra de 21 empresas pesquisadas, perfazendo $75 \%$ do total da região (Figura 2), tendo em vista que algumas inicialmente contatadas recusaram-se a participar da pesquisa de campo no momento da aplicação do questionário, por entenderem que as informações solicitadas seriam de caráter sigiloso.

Teoria e Evidência Econômica - Ano 19, n. 40, p. 102-125, jan./jun. 2013 


\begin{tabular}{|l|c|c|c|c|}
\hline $\begin{array}{c}\text { Porte das } \\
\text { empresas }\end{array}$ & Universo & $\begin{array}{c}\text { Universo } \\
\text { considerado } \\
\text { na pesquisa }\end{array}$ & Amostra & $\begin{array}{c}\text { Fração amostral } \\
\text { final }\end{array}$ \\
\hline Pequenas & 16 & 12 & 10 & $83,33 \%$ \\
\hline Médias & 11 & 9 & 6 & $66,67 \%$ \\
\hline Grandes & 8 & 7 & 5 & $71,43 \%$ \\
\hline Total na mesorregião & 35 & 28 & 21 & $75,00 \%$ \\
\hline Total no RS & 45 & 45 & 21 & $46,67 \%$ \\
\hline
\end{tabular}

Fonte: dados da pesquisa.

Figura 2: Universo, amostra e frações amostrais coletadas na pesquisa de campo

Em virtude desses fatores, a pesquisa foi realizada a partir de uma amostra obedecendo a um processo quase aleatório com repetição. Para a classificação do tamanho das empresas, utilizaram-se critérios do Finame para o BNDES (2003), a saber: pequenas empresas - receita operacional bruta anual ou anualizada inferior ou igual a $\mathrm{R} \$ 7.875$ mil; médias empresas - receita operacional bruta anual ou anualizada superior a $\mathrm{R} \$ 7.875$ mil e inferior ou igual a $\mathrm{R} \$ 45$ milhões; grandes empresas - receita operacional bruta anual ou anualizada superior a $R \$ 45$ milhões.

Como a estimação de parâmetros populacionais não é o objetivo principal da pesquisa, e sim a identificação da correlação entre as variáveis (características e padrões de decisões), as frações amostrais de cada estrato não precisam ser necessariamente iguais à fração de cada subpopulação (estratificação proporcional). Os estratos analisados podem ser iguais para efeitos de simplificação e de conveniência (estratificação desproporcional) (HOFFMANN, 1991; GUJARATI, 2000; SARTORIS, 2003).

Tendo em vista que as decisões de posicionamento das empresas podem variar para cada produto comercializado, a fim de evitar esse problema e de avaliar padrões de decisão, aplicou-se um questionário no qual foram estabelecidas, para a análise, duas categorias de produto (Stock Keeping Unit [SKU]); ou seja, solicitou-se que cada empresa respondesse ao mesmo conjunto de perguntas, avaliando dois produtos distintos (SKUs diferentes). O primeiro conjunto de respostas referiu-se a um SKU de grande representatividade para o faturamento da empresa, (SKU classe A), ao passo que o segundo avaliou um SKU de baixa representatividade em faturamento (SKU classe C). 


\subsection{Medidas de dispersão e hipóteses a serem testadas}

Considerando a perspectiva do setor de máquinas e implementos agrícolas, a pergunta principal a ser respondida por meio da pesquisa de campo sobre o nível transversal da criação de posições competitivas na logística foi: quais são as características do produto, da operação e da demanda significativamente correlacionadas com as decisões logísticas individuais e com os tipos de organização do fluxo de produtos?

Para fins de orientação da pesquisa, essa pergunta geral se desdobra em duas perguntas específicas, passíveis de falseamento, a partir de testes de hipóteses. Primeiro, quais são as características do negócio significativamente correlacionadas com as decisões individuais de (1) coordenação de fluxo de produtos, (2) alocação de estoques e (3) base para acionamento da fabricação de produtos acabados? Segundo, quais são as características do produto, da operação e da demanda significativamente correlacionadas com os tipos de organização do fluxo de produtos: empurrar/descentralizar/para estoque, empurrar/centralizar/para estoque, puxar/ descentralizar/para estoque, puxar/descentralizar/contrapedido, puxar/centralizar/para estoque e puxar/centralizar/contrapedido?

A resposta a essas questões permitiu a proposição de quadros conceituais de apoio à tomada de decisão com relação às deliberações logísticas individuais e aos tipos de organização do fluxo de produtos. Com base nesses quadros, pôde-se refletir sobre a lógica e o referencial teórico que sustentam a avaliação transversal, permitindo, então, a identificação de padrões decisórios mais aderentes a determinado conjunto de características do negócio.

Para o teste dessas hipóteses, foram utilizadas medidas de dispersão, tais como médias, medianas, desvio-padrão, variância e coeficiente de variação. Em particular, foi utilizado o coeficiente de variação para uma distribuição bidimensional, na medida em que se está interessado na relação entre duas variáveis significativamente correlacionadas, isto é: a) tomadas de decisões versus cada característica do negócio (produto, operação, demanda); b) tipos de organização do fluxo de produtos versus cada característica do negócio.

\subsection{Operacionalização, descrição das variáveis e formas de interpretação das características do negócio}

As variáveis que foram coletadas para o cálculo das correlações estão listadas na Figura 3, onde também consta a descrição das escalas empregadas para a mensuração das características do negócio e das decisões logísticas. As variáveis foram operacionalizadas por meio da variável binária ( 0 ou 1 ). 
A interpretação dos resultados em relação às decisões logísticas individuais de coordenação do fluxo de produtos (empurrar versus puxar), alocação de estoques (centralizado versus descentralizado) e base para acionamento da fabricação de produtos acabados (contrapedido versus para estoque) dá-se da seguinte forma:

a) Coordenação do fluxo de produtos: corresponde ao elo da cadeia de distribuição que comanda o fluxo de produtos, que, por sua vez, vai do elo de produção (fábrica) até os clientes, passando ou não pelos elos intermediários. Assim, quando o fluxo de produtos passa pelo elo da produção, na fábrica, ou pela administração central, que é considerada o elo inicial da cadeia que coordena o fluxo, diz-se que o fluxo é empurrado. Já quando o fluxo de produtos passa pelo varejista ou pela demanda, segundo e terceiro elos que decidem sobre o início do fluxo, diz-se que o fluxo é puxado. Essa decisão de coordenação do fluxo de produtos é básica para a estratégia de posicionamento logístico, a qual afeta fortemente todas as outras decisões, sobretudo a política de produção. Essa coordenação pode ser relacionada como: mais próximo do cliente final, "puxar"; mais próximo do fornecedor inicial, "empurrar".

\begin{tabular}{|c|c|}
\hline \multirow{2}{*}{ Características do negócio } & Definição \\
\hline & Características do produto \\
\hline Custo do produto vendido (CPV) & $\begin{array}{l}\text { E o volume de capital de giro necessário para produzir uma unidade } \\
\text { adicional. }\end{array}$ \\
\hline Densidade de valor (DV) & É a divisão do CPV pelo peso do produto. \\
\hline Grau de obsolescência (GO) & É o inverso do tempo do ciclo de vida do produto. \\
\hline Grau de perecibilidade (GP) & É o inverso do prazo de validade dos produtos. \\
\hline \multicolumn{2}{|r|}{ Características da demanda } \\
\hline Giro de estoque (GE) & $\begin{array}{l}\text { E a divisão do número de dias do ano pelo número de dias de venda } \\
\text { em estoque do produto. }\end{array}$ \\
\hline Amplitude de vendas (AV) & $\begin{array}{l}\text { E a divisão da venda mensal máxima pela venda mensal mínima de } \\
\text { um produto. }\end{array}$ \\
\hline Visibilidade da demanda (VD) & $\begin{array}{l}\text { Quando acessa informações de venda pelo menos de seu principal } \\
\text { cliente. (Se sim, então }=1 \text {; se não }=0 \text { ). }\end{array}$ \\
\hline Concorrentes diretos (CD) & É o número total de concorrentes. \\
\hline Prazo de entrega (PE) & É o prazo desde a colocação do pedido pelo cliente até sua entrega. \\
\hline \multicolumn{2}{|r|}{ Características da operação } \\
\hline Tempo de resposta (TR) & $\begin{array}{l}\text { E o somatório do tempo de recebimento do insumo mais demorado } \\
\text { com o tempo de entrega do produto para o principal cliente. }\end{array}$ \\
\hline $\begin{array}{l}\text { Grau de complexidade no } \\
\text { fornecimento (GCF) }\end{array}$ & $\begin{array}{l}\text { E a multiplicação do número de fornecedores pelo número de itens } \\
\text { de matéria-prima. }\end{array}$ \\
\hline Razão entre prazos (RP) & $\begin{array}{l}\text { E o coeficiente entre o prazo de entrega do produto acabado para o } \\
\text { cliente e o prazo de entrega da matéria-prima pelo fornecedor. }\end{array}$ \\
\hline \multicolumn{2}{|r|}{ Organização do fluxo de produtos acabados } \\
\hline Coordenação do fluxo de produtos & Puxar $=1 \quad$ Empurrar $=0$ \\
\hline Alocação de estoques & Centralizar $=1 \quad$ Descentralizar $=0$ \\
\hline Base para acionamento da fabricação & Contrapedido $=1 \quad$ Para estoque $=0$ \\
\hline
\end{tabular}

Fonte: elaborado com base em Wanke (2003) e Pagh e Cooper (1998).

Figura 3: Operacionalização e estatísticas descritivas das variáveis coletadas na pesquisa de campo 
A decisão entre puxar ou empurrar depende da análise conjunta de dois fatores: visibilidade da demanda, a qual permite que os fluxos de produtos sejam puxados, ou seja, coordenados pelo estágio mais próximo do consumidor final, com base nas informações de venda em tempo real capturadas pela tecnologia de informação; e prazo de entrega para o cliente final, o qual se refere ao tempo médio de recebimento do insumo mais demorado para a produção e de entrega do produto para o cliente. Essa análise conjunta pode proporcionar uma resposta imediata sobre quanto tempo o cliente precisaria esperar para ter o produto em mãos quando o estoque é zero. Conforme o autor, longos prazos de entrega favoreceriam que a coordenação do fluxo de produtos fosse puxada com base na demanda real e prazos mais curtos exigiriam que o fluxo de produtos fosse empurrado com base em previsões de venda.

b) Alocação de estoques: relacionada com o número de pontos de armazenagem na cadeia de distribuição do produto. Pode ser de duas formas: "centralizada" e "descentralizada". A centralização dos estoques significa postergar ao máximo o transporte dos produtos, somente os movimentando quando o cliente final realizar seu pedido, ou seja, quando existir apenas um ponto de armazenagem na cadeia de distribuição. A descentralização dos estoques consiste em antecipar seu transporte/sua movimentação por outras instalações intermediárias no presente, com base em previsões de vendas futuras.

Diferentes características do produto, da operação e da demanda podem afetar a centralização ou a descentralização dos estoques de produto acabado. De acordo com a literatura, as características do produto que afetam a alocação dos estoques englobam a DV, o CPV e o GO. Ballou (1992) e Christopher (2002) afirmam que, quanto maiores forem os custos do produto vendido, a densidade de custos e a obsolescência, tanto maior será a tendência para a centralização dos estoques. Produtos com maior CPV e maior GO tendem a ficar centralizados em razão de maiores custos de oportunidade de manter estoque e de maiores riscos de perda, respectivamente. Em contrapartida, produtos com menor DV refletem maior necessidade de minimizar os custos unitários de distribuição, assegurando, assim, sua competitividade em preço. A descentralização permite a consolidação de carregamentos e a consequente diluição dos custos fixos de distribuição por número de produtos (JAYARAMAN, 1998). Já as características da demanda e da operação que influenciam na alocação dos estoques englobam o GE e a AV. Waters (1992), assim como Mentzer, Kahn e Bienstock (1998), argumenta que, dentro dessas características da demanda, quanto menor for a amplitude de vendas e maior o giro de estoques, tanto maior será a propensão para a descentralização dos estoques, basicamente porque são minimizados os riscos associados ao encalhe do produto. 
c) Base para o acionamento da fabricação de produtos acabados: conforme Wanke (2002), isso pode ser iniciado de duas formas: "contrapedido" e "para estoque". Quando a produção é feita para estoque, considera-se que há uma antecipação no tempo, tendo em vista que a quantidade a ser produzida foi antecipada por uma previsão de venda; ou seja, trata-se de comprar e transformar insumos em produtos acabados no presente momento e em antecipação à demanda futura, com base em previsões de vendas. Quando a produção é feita contrapedido, significa que foram postergadas ao máximo no tempo a compra e a transformação de insumos em produto acabado, que somente é feito quando confirmado o pedido.

Algumas características do produto e da operação que influenciam essa decisão são o CPV, o GO e a RP. Assim, quanto maior for o CPV, tanto maior será a propensão para produzir contrapedido. Analogamente, quanto maior for a obsolescência, maior será a propensão para produzir contrapedido, a fim de evitar perdas de estoques. Finalmente, quanto maior for a razão entre prazos, maior será o prazo de entrega dos produtos aos clientes em comparação ao prazo de entrega das matérias-primas pelo fornecedor.

\subsection{Operacionalização, descrição das variáveis e formas de interpretação dos tipos de organização do fluxo de produtos}

Uma vez apresentadas as decisões logísticas relevantes para a definição e a caracterização do fluxo de produtos, Leeuw e Goor (1999) afirmam que uma consideração adicional, com relação à sua natureza, deve ser feita para melhor compreensão da tipologia para a organização do fluxo de produtos. A partir das dimensões de responsabilidade, espaço e tempo, as três decisões logísticas podem ser combinadas em diferentes tipos de organização do fluxo de produtos.

Wanke (2003a) enfatiza que, teoricamente, existem pelo menos oito modos distintos de uma empresa organizar seu fluxo de produtos, fazendo a combinação entre as duas alternativas de cada categoria de decisão (Figura 4). No entanto, desses oito supostos tipos, apenas seis poderiam ocorrer na prática: empurrar/descentralizar/para estoque, empurrar/centralizar/para estoque, puxar/descentralizar/ para estoque, puxar/descentralizar/contrapedido, puxar/centralizar/para estoque, puxar/centralizar/contrapedido. A explicação lógica é que a decisão de produzir contrapedido depende, exclusivamente, da reação à demanda real (puxar), e não de previsão de vendas (empurrar). Devido a essa restrição, eliminam-se as combinações empurrar/descentralizar/contrapedido e empurrar/centralizar/contrapedido. 


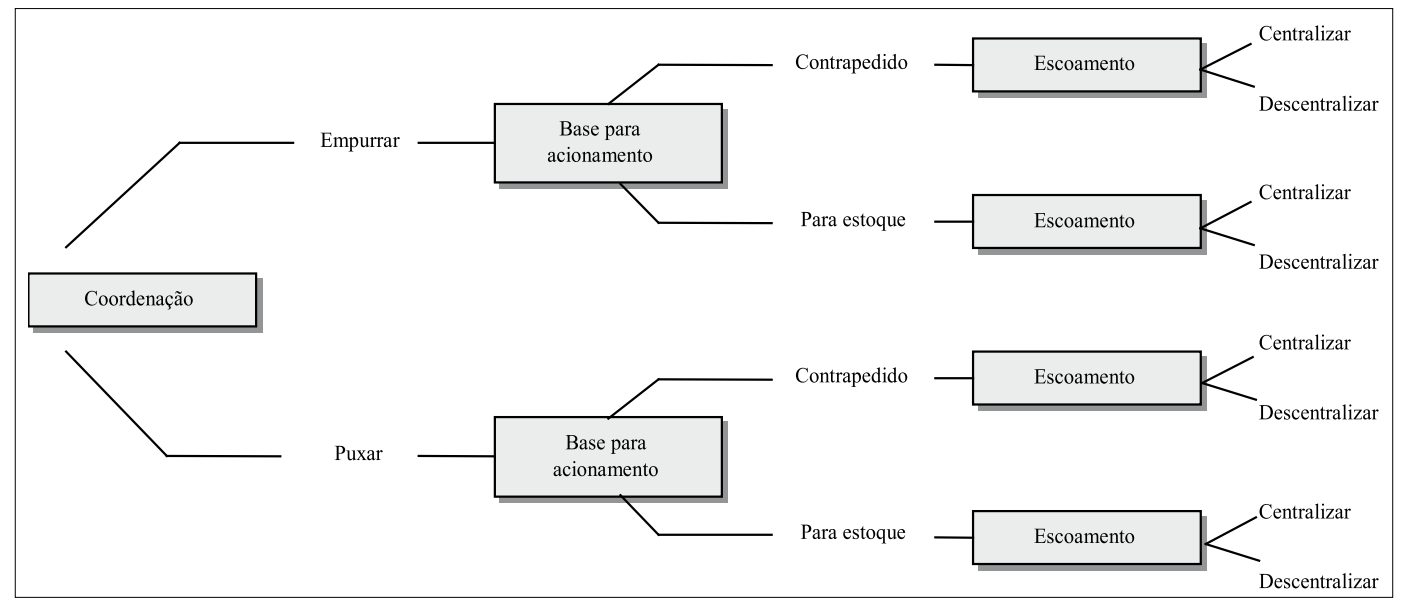

Fonte: elaborado com base em Wanke (2001).

Figura 4: Oito tipos de organização de fluxo de produtos

A identificação da organização dos fluxos de produtos foi feita de forma direta com base nas informações coletadas nas empresas, e os seis tipos possíveis de organização dos fluxos foram operacionalizados por meio da variável binária ( 0 ou 1$)$, como mostra a Figura 5.

\begin{tabular}{|l|ll|}
\hline \multicolumn{1}{|c|}{ Tipos de organização do fluxo de produtos } & \multicolumn{2}{c|}{ Definição } \\
\hline Empurrar/descentralizar/para estoque & Sim $=1 \quad$ Não $=0$ \\
\hline Puxar/descentralizar/para estoque & $\operatorname{Sim}=1$ & Não $=0$ \\
\hline Empurrar/centralizar/para estoque & $\operatorname{Sim}=1 \quad$ Não $=0$ \\
\hline Puxar/centralizar/para estoque & $\operatorname{Sim}=1 \quad$ Não $=0$ \\
\hline Puxar/descentralizar/contrapedido & $\operatorname{Sim}=1 \quad$ Não $=0$ \\
\hline Puxar/centralizar/contrapedido & Sim $=1 \quad$ Não $=0$ \\
\hline
\end{tabular}

Fonte: elaborado com base em Wanke (2003) e Pagh e Cooper (1998).

Figura 5: Tipos de organização do fluxo de produtos e operacionalização estatística a ser implementada

A determinação dos impactos das características do negócio na organização do fluxo de produtos estabeleceu-se por meio de correlações significativas do tipo positivas ou negativas. Com isso, identificaram-se alguns padrões de decisão empresarial do setor. 


\subsection{Características do questionário da pesquisa de campo}

O questionário foi elaborado por pesquisadores do Centro de Estudos em Logística do Coppead/RJ (2001), e seus itens permitem caracterizar as decisões logísticas de cada empresa, assim como as características do negócio em que atuam. $\mathrm{O}$ instrumento é composto por questões factuais, as quais assim foram definidas por simplificarem o projeto do questionário, pois foram formuladas diferentes alternativas para uma mesma pergunta. Outra vantagem é a possibilidade de o entrevistador interagir com o entrevistado, de modo a assegurar o correto entendimento das perguntas.

Em todas as empresas componentes da amostra, obteve-se a participação de duas pessoas, entre gerentes e supervisores responsáveis pela área de produção e logística, que responderam ao questionário, perfazendo um total de 42 entrevistados.

\section{Correlações das características do negócio com as decisões logísticas e com os tipos de organização dos fluxos de produtos}

As análises de correlações no setor de máquinas e implementos agrícolas da mesorregião Noroeste Rio-Grandense foram divididas em duas partes. Assim, num primeiro momento, apresentam-se as análises de correlação entre as características do negócio e as decisões de coordenação do fluxo de produtos, alocação de estoques e base para acionamento da fabricação de produtos acabados, bem como a mediana das características do negócio correlacionadas com as categorias de decisão; ou seja, quantifica-se sob quais circunstâncias o fluxo de produtos deverá ser puxado ou empurrado, centralizado ou descentralizado, produzido contrapedido ou para estoque. Num segundo momento, expõem-se as análises de correlação entre as características do negócio e os tipos de organização do fluxo de produtos. Os resultados são divulgados e discutidos separadamente para cada análise, demonstrados tanto para o setor quanto para os diferentes portes das empresas.

\subsection{Impactos das características do negócio sobre as decisões logísticas}

Considerando que a maior competitividade pode ser alcançada de acordo com as estratégias de posicionamento logístico, as categorias de decisão devem permanecer, ao longo do tempo, de forma articulada e coerente entre si, permitindo 
que uma empresa atinja seus objetivos de minimização de custo total para um determinado nível de serviços. A seguir, são apresentadas as categorias de decisão correlacionadas com as características do negócio para o setor e para os diferentes portes das empresas.

a) A decisão de coordenação do fluxo de produtos apresentou correlações estatisticamente significativas com algumas características do produto, da demanda e da operação, tanto para o setor como um todo como para as empresas de porte médio e pequeno, conforme pode ser observado na Tabela 1. No entanto, as grandes empresas não apresentaram qualquer correlação, tendo em vista que tanto o SKU classe A como o SKU classe C são totalmente baseados na decisão de puxar o fluxo de produtos. Os resultados das correlações mostram que os principais motivadores para a estruturação da coordenação do fluxo de produtos acabados, num contexto geral do setor, são o longo ciclo de vida dos produtos, o elevado custo de manter estoques, o giro de estoque, o fato de os clientes aceitarem prazos maiores de entrega para receberem produtos (em virtude de dependência de cartas de crédito ou financiamento bancário), bem como a demanda de máquinas e/ou implementos agrícolas, que, nos últimos anos, foi crescentemente maior que a oferta em razão das boas safras.

Tabela 1: Correlações significativas entre as categorias de decisão e as características do negócio no setor de máquinas e implementos agrícolas (Setor: $\mathrm{N}=42$; Grandes: $\mathrm{N}=10$; Médias: $\mathrm{N}=12$; Pequenas: $\mathrm{N}=20$ )

\begin{tabular}{|c|c|c|c|c|c|c|c|c|c|c|c|c|}
\hline \multirow{3}{*}{$\begin{array}{c}\text { Categorias } \\
\begin{array}{c}\text { Características } \\
\text { do produto }\end{array}\end{array}$} & \multicolumn{4}{|c|}{$\begin{array}{l}\text { Coordenação do fluxo } \\
\text { de produtos }\end{array}$} & \multicolumn{4}{|c|}{ Alocação de estoques } & \multicolumn{4}{|c|}{$\begin{array}{l}\text { Base } \mathrm{p} / \text { acionam. fabric. de } \\
\text { produtos acabados }\end{array}$} \\
\hline & \multicolumn{2}{|c|}{ Puxar $=1$} & \multicolumn{2}{|c|}{ Empurrar $=0$} & \multicolumn{2}{|c|}{ Centralizar $=1 \quad \mathrm{D}$} & \multicolumn{2}{|c|}{ Descentralizar $=0$} & \multicolumn{2}{|c|}{ Contrapedido $=1$} & \multicolumn{2}{|c|}{ Para estoque $=0$} \\
\hline & Setor & G & M & $P$ & Setor & $G$ & $M$ & $\mathrm{P}$ & Setor & $\mathrm{G}$ & M & $\mathrm{P}$ \\
\hline$\overline{\mathrm{CPV}}$ & $0,339^{(\mathrm{b})}$ & & $0,445^{(\mathrm{d})}$ & $0,299^{(d)}$ & $-0,392^{(a)}$ & & $-0,442^{(\mathrm{d})}$ & & $0,354^{(\mathrm{b})}$ & & $0,445^{(\mathrm{d})}$ & \\
\hline DV & & & & & & & & & $-0,342^{(b)}$ & & & $-0,320^{(d)}$ \\
\hline GO & $-0,365^{(b)}$ & & $-0,546^{(b)}$ & & & & & & $-0,233^{(d)}$ & & $-0,546^{(b)}$ & \\
\hline GP & & & & & & & & & & & & \\
\hline Da demanda & & & & & & & & & & & & \\
\hline GE & $0,284^{(0)}$ & & & $0,540^{(a)}$ & & & & & $0,292^{(c)}$ & & & $0,585^{(a)}$ \\
\hline AV & & & $-0,451^{(c)}$ & & & & & & & & $-0,451^{(c)}$ & 0 \\
\hline VD & & & & & & & & & & & & $0,361^{(c)}$ \\
\hline CD & & & & & & & & & & & & 0 \\
\hline PE & $0,397^{(a)}$ & & $0,433^{(d)}$ & $0,350^{(d)}$ & $-0,247^{(\mathrm{d})}$ & $-0,429^{(d)}$ & & & $0,484^{(a)}$ & & $0,433^{(d)}$ & $0,426^{(b)}$ \\
\hline Da operação & & & & & & & & & & & & \\
\hline TR & $0,383^{(b)}$ & & $0,597^{(\text {b) }}$ & & $-0,344^{(b)}$ & $-0,585^{(b)}$ & & & $0,482^{(a)}$ & & $0,597^{(b)}$ & \\
\hline GCF & & & & & $-0,559^{(\mathrm{a})}$ & $-0,841^{(a)}$ & $-0,409^{(d)}$ & & & & & $00,286^{(d)}$ \\
\hline RP & $0,233^{(d)}$ & & & $0,335^{(\mathrm{d})}$ & & & & & & & & \\
\hline
\end{tabular}

Fonte: Dados da pesquisa.

OBS.: $G$ = Grandes empresas; $M=$ Médias empresas; $P$ = Pequenas empresas. Grau de significância = 0,01; (b) Grau de significância $=0,05$; (c) Grau de significância $=0,10$; (d) Grau de significância $=0,20$ 
Nessa categoria de decisão, algumas características do negócio merecem destaque. A correlação positiva com o CPV, tanto do setor como das médias e pequenas empresas, indica que, quanto mais caros os produtos, mais tendem a ser puxados, pois as empresas se mostram mais propensas a retardar a sua fabricação até que a informação esteja disponível. O PE, o TR e a RP, que apresentaram correlação positiva, também indicam que, quanto maior for o tempo de tramitação entre fornecedor/fábrica/consumidor, tanto maior será a propensão para reagir à demanda (puxar).

b) A decisão de alocação de estoques, para o setor e para as grandes e médias empresas, apresentou correlações estatisticamente significativas apenas com CPV, PE, TR e GCF (Tabela 1). Porém, as empresas de pequeno porte não apresentaram correlações, pelo fato de serem, para ambos os SKUs, totalmente centralizadas, indicando, em termos gerais para o setor, uma tendência maior à centralização de estoques. Cabe salientar que, nessa categoria de decisão, como as correlações se apresentaram negativas em todas as características do negócio com significância (tanto para o setor como para os portes), os resultados corroboram que a decisão de centralizar os estoques somente deverá ser tomada na fabricação de produtos com baixo CPV, PE e TR curtos e GCF baixos. Ressalta-se que, de acordo com os dados, as grandes empresas não deverão tomar decisões baseadas em CPV, e sim nas demais características correlacionadas, ao passo que as empresas de médio porte deverão basear-se, para centralizar seus estoques, sobretudo nos custos adicionados aos seus produtos.

c) $\mathrm{Na}$ decisão de base para o acionamento da fabricação de produtos acabados, encontraram-se correlações estatisticamente significativas com CPV, DV, GO, GE, AV, VD, PE, TR e GCF, distribuídos no setor, nas pequenas e médias empresas. Já as empresas de grande porte, do mesmo modo que na decisão de coordenação do fluxo de produtos, não apresentaram correlações significativas, uma vez que, para ambas as categorias de produtos pesquisados, são totalmente feitas contrapedido (Tabela 1). Conforme Christopher (1997) e Wanke (2001), muitas características da decisão de puxar ou empurrar são as mesmas que afetam a decisão de alocação dos estoques de produtos, devido ao fato de os fluxos de produtos empurrados dependerem, necessariamente, de previsão de vendas, ao passo que os fluxos de produtos puxados são, em sua maioria, uma resposta à demanda final.

Os resultados, no contexto geral do setor, apontam que a decisão de base para acionamento da fabricação dos produtos é influenciada por características que refletem os riscos e os custos associados à manutenção dos estoques (CPV, DV, GO), ao nível de concorrência dos mercados $(\mathrm{GE}$ e $\mathrm{PE})$ e à necessidade de resposta rápida aos clientes (TR), indicando que as empresas desse setor fabricam a maior parte de seus produtos contrapedido. 


\subsubsection{Mediana das características do negócio correlacionadas com as categorias de decisão}

Considerando que a mediana de um conjunto de dados é o valor tal que metade dos dados são iguais ou inferiores a esse valor e metade dos dados são iguais ou superiores a esse valor, o cálculo da mediana para cada uma das características do negócio correlacionadas com as decisões logísticas constitui-se num quadro conceitual de apoio à tomada de decisão no setor de máquinas e implementos agrícolas.

a) Pela mediana da decisão de coordenação do fluxo de produtos, a Tabela 2 mostra sob que patamar a produção deverá ser fabricada com base na demanda final (puxar) ou numa previsão de vendas (empurrar). Dessa forma, quando analisadas as medianas por porte, as empresas de porte médio mostraram-se muito semelhantes ao setor; por sua vez, as empresas de pequeno porte apresentaram magnitudes bastante distintas no CPV (superior a $\mathrm{R} \$ 6.100,00$, puxar; inferior a $\mathrm{R} \$ 1.200,00$, empurrar), no GE (acima de 73 vezes, puxar; abaixo de oito vezes, empurrar) e no PE (acima de sete dias, puxar; abaixo de dois dias, empurrar). Cabe destacar que as medianas reforçam o que a análise das correlações evidenciou: a decisão de puxar ou empurrar é afetada pela variável $\mathrm{PE}$, corroborando a afirmação de Christopher (2000), mas contrapondo a tese defendida pelo autor quanto à visibilidade da demanda, a qual, no setor analisado, praticamente inexiste.

b) Na decisão de alocação dos estoques, quantificando sob quais circunstâncias os estoques deverão ser centralizados ou descentralizados de forma a proporcionar um bom desempenho das empresas, a Tabela 2 indica, para o setor, que, quando o CPV for inferior a $\mathrm{R} \$ 7.000,00$, o $\mathrm{PE}$, inferior a sete dias, o TR, inferior a 35 dias e o GCF, inferior a 1.350, os estoques deverão ser centralizados. Por sua vez, deverão ser descentralizados quando o CPV for superior a $R \$ 50.000,00$, o PE, superior a trinta dias, o TR, superior a sessenta dias e o GCF, superior a 160.000 .

Fazendo-se um comparativo entre as medianas das grandes empresas e as medianas do setor geral, nota-se que os estoques deverão ser centralizados se o prazo de entrega for inferior a um mês (diferentemente do setor, em que era de apenas sete dias) e descentralizado se for superior a 45 dias.

O tempo de resposta, para ser centralizado nas grandes empresas, deverá ser inferior a 75 dias e, para ser descentralizado, superior a 135 dias, ou seja, nas duas situações, o dobro do tempo necessário do que no setor quando analisado como um todo. O grau de complexidade no 
Tabela 2: Parâmetros para a tomada de decisão do posicionamento logístico baseado nas medianas das características do negócio correlacionadas com as categorias de decisão, no setor de máquinas e implementos agrícolas (Puxar $=1$ Empurrar $=0$, Centralizar $=1$ Descentralizar $=0$, Contrapedido $=1$, Para estoque $=0$ ) (Setor: $N=42$; Grandes: $N=10$; Médias: $\mathrm{N}=12$; Pequenas: $\mathrm{N}=20$ ).

\begin{tabular}{l|c|c|c|c|c|c|c|c|c|c|c|c|c|c|c|c|c|}
\hline \multirow{2}{*}{ Categorias } & \multicolumn{5}{|c|}{$\begin{array}{c}\text { Coordenação do fluxo } \\
\text { de produtos }\end{array}$} & \multicolumn{5}{c|}{ Alocação de estoques } & \multicolumn{3}{c|}{ Base para acionamento fabr. produtos } \\
acabados
\end{tabular}

Fonte: dados da pesquisa.

OBS.: $G=$ Grandes empresas; $M=$ Médias empresas; $P=$ Pequenas empresas. $C P V=$ Custo do produto vendido; $D V=$ ensidade de valor; $\mathrm{GO}=\mathrm{Grau}$ de obsolescência; $\mathrm{GP}=\mathrm{Grau}$ de perecibilidade; $\mathrm{GE}=\mathrm{Giro}$ de estoque; $\mathrm{AV}=\mathrm{Amplitude}$ de vendas; $\mathrm{VD}=$ Visibilidade da demanda; $\mathrm{CD}=$ Concorrentes diretos; $\mathrm{PE}=$ Prazo de entrega; $\mathrm{TR}=$ Tempo de resposta; $\mathrm{GCF}=\mathrm{Grau}$ de complexidade no fornecimento; RP= Razão entre prazos.

O fornecimento, para ser centralizado, deverá ser inferior a 18.250 e, para ser descentralizado, superior a 28.500.000 nas grandes empresas. Por sua vez, as empresas de porte médio, a partir das medianas apresentadas, serão centralizadas quando o CPV for inferior a $\mathrm{R} \$ 7.200,00$ e o grau de complexidade no fornecimento for superior a 352; descentralizadas quando o CPV for superior a $\mathrm{R} \$ 51.000,00$ e o grau de complexidade no fornecimento for inferior a 50 .

Apesar das poucas correlações significativas encontradas nessa categoria de decisão, principalmente quando particularizadas aos portes, essas informações podem ser tomadas como um quadro conceitual de apoio à decisão sobre a alocação dos estoques para o setor. Conforme a literatura apresentada, as variáveis GE, GP, GO, AV e DV são as características do negócio que se destacam na determinação de o estoque ser centralizado ou descentralizado. No entanto, nesse setor, ainda que se configurem como fortes argumentos para justificar a centralização do setor, essas variáveis não apresentaram correlações significativas. 
c) Pela mediana da decisão de base para o acionamento da fabricação de produtos acabados, a Tabela 2 indica que a decisão de se produzir contrapedido no setor será tomada quando o CPV for superior a $\mathrm{R} \$ 15.000,00$, a DV for superior a $\mathrm{R} \$ 9,00$, o GO estiver acima de 0,10, o GE, acima de 37 vezes ao ano, o PE, acima de quinze dias e o TR, acima de 55 dias. Já o acionamento da fabricação de produtos será para estoque quando o CPV for inferior a $R \$ 1.200,00$, a DV, menor do que $R \$ 10,00$, o GO, abaixo de 0,13 , o GE, menor do que 37 vezes ao ano, o PE, menor do que cinco dias e o TR, inferior a vinte dias. Quando analisada a mediana por porte, as empresas de porte médio apresentaram certa semelhança com o setor, em termos gerais, mas com variações significativas nas pequenas empresas.

Dado que o setor analisado, conforme pesquisa de campo, demonstrou expressiva tendência de todos os portes em produzirem contrapedido, pelas medianas das características do negócio correlacionadas com a base para acionamento da fabricação de produtos acabados, é importante ressaltar algumas variáveis. Com relação ao CPV, quanto maior for o volume de capital de giro necessário para produzir uma unidade adicional, maior será a necessidade de produzir contrapedido. Através da mediana, reforçaram-se esses resultados, com a demonstração da magnitude dessa característica do produto: produzir contrapedido será considerado uma boa tomada de decisão se ela for superior a $R \$ 15.000$ para o setor e superior a $R \$ 19.500$ para empresas de porte médio; será melhor produzir para estoque produtos com valores abaixo de $\mathrm{R} \$ 1.200$ e $\mathrm{R} \$ 965$, respectivamente. Nas pequenas empresas, pelos resultados das medianas, percebe-se que, para uma política de produção mais segura, deve-se produzir contrapedido, observando-se o giro de estoque (superior a 73 vezes), um bom prazo de entrega (superior a sete dias) e a visibilidade da demanda.

\subsection{Impactos das características do negócio sobre os tipos de organização dos fluxos de produtos}

Os resultados das análises de correlação indicam que diferentes combinações de características do produto, da operação e da demanda influenciam significativamente na adoção de determinado tipo de organização de fluxo de produtos.

Conforme já mencionado, as características do negócio podem ser combinadas em seis situações. No entanto, como resultado no setor de máquinas e implementos agrícolas, as combinações empurrar/descentralizar/para estoque e puxar/descentralizar/para estoque não apresentaram qualquer correlação significativa com as características do negócio, uma vez que, pelos dados colhidos, tanto a descentralização dos estoques como a fabricação de produtos para estoque praticamente inexistem nesse contexto. 
Eis as demais combinações que podem servir de base para a escolha do tipo de organização do fluxo de produtos mais adequados às características das empresas do setor de máquinas e implementos agrícolas:

a) Organização do fluxo de produtos do tipo empurrar/centralizar/ para estoque: este tipo de organização de fluxo de produtos, quando analisado no contexto geral do setor, apresentou-se estatisticamente correlacionado com o CPV e o GO, nas características do produto; GE e PE, nas características da demanda; e TR e RP, nas características da operação (Tabela 3). O sinal dessas correlações indica que esse tipo de organização do fluxo de produtos está relacionado a produtos com baixo CPV, elevado GO, baixo GE, baixo PE, curto TR e baixa RP. Fazendo-se uma análise por porte, separadamente, os resultados mais relevantes indicam que, para as grandes empresas, não se obteve correlação significativa, e que, nas empresas de pequeno e médio porte, as correlações foram bastante semelhantes às do setor. Ressalta-se que os sinais das correlações do setor apresentaram-se iguais aos sinais para os diferentes portes, distinguindo-se apenas no grau de significância destes .

b) Organização do fluxo de produtos do tipo puxar/centralizar/para estoque: essa combinação, quando analisada no setor, apresentou-se estatisticamente correlacionada com as características do negócio de DV, PE e TR (Tabela 3). O sinal dessas correlações indica que esse tipo de organização do fluxo de produtos está relacionado a produtos com alta DV, baixo PE e baixo TR. Entretanto, quando analisado esse tipo de correlação por porte, as grandes e médias empresas não apresentaram qualquer correlação significativa. Por sua vez, as empresas de pequeno porte correlacionaram-se apenas com alta densidade de valor.

c) Organização do fluxo de produtos do tipo puxar/descentralizar/ contrapedido: esse tipo de organização, no setor, é estatisticamente correlacionado com produtos de alto CPV, elevado PE, elevado TR e alto GCF. Numa análise particularizada ao tamanho das empresas, comparada ao setor, as de grande porte tiveram a mesma correlação nas características da demanda e da operação, diferenciando-se apenas nas características do produto, as quais se correlacionaram, nesse tipo de organização de fluxo de produtos, com GP (alto) em vez de CPV, como no setor. As de porte médio tiveram a mesma correlação com as características do produto; não tiveram correlações com a característica da demanda e, na operação, correlacionaram-se apenas com GCF (alto). Por fim, nesse tipo de organização, as pequenas empresas não apresentaram qualquer correlação significativa. 
Tabela 3: Correlações significativas entre os tipos de organização do fluxo de produtos e as características do negócio no setor de máquinas e implementos agrícolas (Setor: $\mathrm{N}=42$; Grandes: N=10; Médias: N=12; Pequenas: N=20).

\begin{tabular}{|c|c|c|c|c|c|c|c|c|c|c|c|c|c|c|c|c|}
\hline \multirow{3}{*}{$\begin{array}{l}\text { Características } \\
\text { do negócio }\end{array}$} & \multicolumn{16}{|c|}{ Tipos de organização do fluxo de produtos $(\mathrm{SIM}=1 \quad \mathrm{NÃO}=0)$} \\
\hline & \multicolumn{4}{|c|}{$\begin{array}{c}\text { Empurrar/centralizar/ } \\
\text { para estoque }\end{array}$} & \multicolumn{4}{|c|}{$\begin{array}{c}\text { Puxar/centralizar/ } \\
\text { para estoque }\end{array}$} & \multicolumn{4}{|c|}{$\begin{array}{c}\text { Puxar/descentralizar/ } \\
\text { contrapedido }\end{array}$} & \multicolumn{4}{|c|}{$\begin{array}{l}\text { Puxar/centralizar/ } \\
\text { contrapedido }\end{array}$} \\
\hline & Setor & G & $\mathrm{M}$ & $\mathrm{P}$ & Setor & G & M & $\mathrm{P}$ & Setor & G & $\mathrm{M}$ & $\mathrm{P}$ & Setor & G & $\mathrm{M}$ & $\mathrm{P}$ \\
\hline Produto & & & & & & & & & & & & & & & & \\
\hline CPV & $-0,339^{(b)}$ & & $-0,445^{(\mathrm{d})} \mid$ & $-0,299^{\text {(d) }}$ & & & & & $0,392^{(a)}$ & & $0,442^{(d)}$ & & & & & \\
\hline $\begin{array}{l}\text { DV } \\
\text { GO }\end{array}$ & $0,365^{(\mathrm{b})}$ & & $0,546^{(b)}$ & & $0,313^{(b)}$ & & & $0,294^{\text {(d) }}$ & & & & & $-0,318^{(b)}$ & & & $-0,320^{\text {(d) }}$ \\
\hline GP & & & & & & & & & & $0,525^{(c)}$ & & & & $-0,525^{(c)}$ & $0,485^{(c)}$ & \\
\hline $\begin{array}{l}\text { GE } \\
\text { AV }\end{array}$ & $-0,284^{(\mathrm{c})}$ & & $0,451^{(\mathrm{c})}$ & $-0,540^{(a)}$ & & & & & & & & & $0,250^{\text {(d) }}$ & & $-0,425^{(d)}$ & $0,585^{(a)}$ \\
\hline $\begin{array}{l}\mathrm{VD} \\
\mathrm{CD}\end{array}$ & & & & & & & & & & & & & & & & $0,361^{(\mathrm{c})}$ \\
\hline $\begin{array}{l}\text { PE } \\
\text { Operação }\end{array}$ & $-0,397^{(a)}$ & & $-0,433^{(\mathrm{d})}$ & $-0,350^{(d)}$ & $-0,207^{(d)}$ & & & & $0,247^{(d)}$ & $0,429^{(\mathrm{d})}$ & & & $0,290^{(c)}$ & $-0,429^{\text {(d) }}$ & $0,430^{(d)}$ & $0,426^{(b)}$ \\
\hline $\begin{array}{l}\text { TR } \\
\text { GCF }\end{array}$ & $-0,383^{(b)}$ & & $-0,597^{(b)}$ & & $-0,224^{(d)}$ & & & & $\begin{array}{l}0,344^{(\text {b) }} \\
0,559^{(a)}\end{array}$ & \begin{tabular}{|l|}
$0,585^{(\text {b) }}$ \\
$0,841^{(a)}$
\end{tabular} & $0,409^{(\mathrm{d})}$ & & $\begin{array}{r}0,225^{(\mathrm{d})} \\
-0,225^{(\mathrm{d})}\end{array}$ & $\begin{array}{l}-0,585^{(\mathrm{b})} \\
-0,841^{(\mathrm{a})}\end{array}$ & $0,560^{(b)}$ & $0,286^{\text {(d) }}$ \\
\hline RP & $-0,233^{(d)}$ & & & $-0,335^{(d)}$ & & & & & & & & & & & & \\
\hline
\end{tabular}

Fonte: dados da pesquisa.

OBS.: $G=$ Grandes empresas; $M=$ Médias empresas; $P=$ Pequenas empresas. Grau de significância $=0,01$; (b) Grau de significância =0,05; (c) Grau de significância =0,10; (d) Grau de significância =0,20

d) Organização do fluxo de produtos do tipo puxar/centralizar/contrapedido: numa análise do setor como um todo, o sinal das correlações indica que a adoção desse tipo de organização do fluxo de produtos está relacionada com produtos de baixa DV, elevado GE, elevado PE, elevado TR e baixo GCF. Analisando, separadamente, por porte e comparando com o setor, observa-se que as grandes empresas tiveram a mesma correlação nas características da operação; nas características da demanda, apenas correlacionaram-se com PE (baixo) e, nas características do produto, em vez de se correlacionarem com DV, apresentaram correlação com GP (baixo). As empresas de porte médio correlacionaram-se em GP (alto), AV (baixa), PE (elevado) e TR (elevado). Destaca-se que apenas os dois últimos itens (PE e TR) apresentaram-se da mesma forma que o setor geral. Já as pequenas empresas, nas características do produto, tiveram a mesma correlação; nas características da demanda, além do GE e PE, correlacionaram-se com VD (baixa) e, nas características da operação, apenas com o GCF.

É pertinente mencionar que esse tipo de organização do fluxo de produtos puxar/centralizar/contrapedido foi o único que se mostrou estatisticamente correlacionado com os diferentes portes das empresas, o que vem a corroborar dados apresentados e as diferentes formas de análises referentes às categorias de decisão, uma vez que a decisão de puxar, centralizar e produzir contrapedido é uma característica observada tanto para as pequenas como para as médias e grandes empresas, podendo ser essa a chave para a segmentação de eventual estratégia logística no setor. 


\section{Conclusões}

Considerando a hipótese de que as diferentes características do produto, da operação e da demanda constituem-se no meio ambiente determinante dos padrões de decisões logísticas e, consequentemente, da organização do fluxo de produtos, ficou evidente que as características do negócio influenciam nas decisões de posicionamento logístico das empresas. Entretanto, as correlações entre as características do negócio e as decisões logísticas mostraram que nem todas as características avaliadas impactam, de forma direta, as decisões de posicionamento logístico empresarial no setor, embora se deva salientar um número considerável de correlações significativas que corroboram grande parte das evidências relatadas na literatura.

No tocante à coordenação do fluxo de produtos, entre as várias correlações significativas, enfatizou-se, com maior veemência, que essa categoria de decisão é fortemente influenciada pelo CPV, tanto do setor como das médias e pequenas empresas (inclusive das grandes, que foram totalmente puxadas). Isso indica que, quanto mais caros são os produtos, mais tendem a ser puxados, pois as empresas se mostram mais propensas a retardar a fabricação dos produtos, até que a informação esteja disponível. Assim, também o prazo de entrega, o tempo de resposta e a razão entre prazos, que apresentaram correlação positiva, indicam que, quanto maior for o tempo de tramitação entre fornecedor/fábrica/consumidor, tanto maior será a propensão para reagir à demanda (puxar).

Já na decisão de alocação de estoques, em virtude de as correlações terem se apresentado negativas em todas as características do negócio com significância, tanto para o setor como para os diferentes portes, os resultados corroboram que a decisão de centralizar os estoques somente deverá ser tomada na fabricação de produtos com baixo CPV, prazo de entrega e tempo de resposta curtos e baixo grau de complexidade no fornecimento. As pequenas empresas, por seu turno, não apresentaram correlações significativas, pois ambas as categorias de produtos analisadas são totalmente centralizadas. Esses resultados assinalam que a decisão de alocação de estoques é influenciada por características que refletem os riscos associados à manutenção dos estoques (CPV e PE), ao nível de concorrência do mercado (TR) e à necessidade de assegurar vendas garantidas por meio do aproveitamento de cartas de crédito ou financiamentos bancários. Por fim, na decisão de base para acionamento da fabricação de produtos acabados, os resultados apontaram que essa decisão é influenciada, principalmente, pela necessidade de resposta rápida aos clientes, indicando que as empresas desse setor fabricam a maior parte de seus produtos contrapedido.

No tocante aos resultados das correlações e das medianas no setor, na coordenação do fluxo de produtos, a decisão de puxar ou empurrar está relacionada ao prazo de entrega, sobretudo para as pequenas empresas, evidenciando, para o setor, que, conforme diminui o porte, a rapidez na entrega do produto ao cliente aumenta. Já pela mediana da alocação de estoques, destacou-se, para o setor e para as médias empresas, que estas deverão tomar a decisão de centralizar ou não com

Teoria e Evidência Econômica - Ano 19, n. 40, p. 102-125, jan./jun. 2013 
base no CPV, e as pequenas empresas, de acordo com o prazo de entrega e o tempo de resposta, os quais se apresentaram muito superiores aos demais portes.

A respeito da base para acionamento da fabricação de produtos acabados, na análise por tamanho das empresas, verificou-se, para o porte médio, que, com base no CPV, será considerada como uma boa tomada de decisão produzir contrapedido se este for superior a $\mathrm{R} \$ 19.500,00$ (maior que o setor) e, para estoque, se for abaixo de $\mathrm{R} \$ 965,00$ (menor que o setor). Nas pequenas empresas, notou-se, pelos resultados das medianas, que, para uma política de produção mais segura, deve-se produzir contrapedido, observando-se o giro de estoque (superior a 73 vezes ao ano), um bom prazo de entrega (superior a sete dias) e tendo visibilidade da demanda. Assim, baseados nas correlações significativas e reforçados pelas fronteiras demonstradas pelas medianas das características do negócio, esses resultados podem contribuir, em grande medida, com gerentes e/ou administradores das empresas na orientação sobre o melhor patamar de decisão logística, direcionando-os a um melhor planejamento na fabricação de produtos, maior agilidade e satisfação ao cliente.

Por conseguinte, quando avaliado o impacto das características do negócio sobre os tipos de organização dos fluxos de produtos, os resultados evidenciaram que a tomada de decisão mais adequada às características das empresas do setor de máquinas e implementos agrícolas, independentemente do porte, foi a combinação puxar/centralizar/contrapedido. Além de corroborar os dados apresentados e as diferentes formas de análises referentes às categorias de decisão, isso leva à conclusão de que, basicamente, a tomada de decisão para fabricação dos produtos fundamenta-se na demanda final; os estoques são centralizados num único ponto de armazenagem e somente se fabrica quando há a confirmação do pedido pelo cliente. Portanto, os resultados mostram que essa combinação se constitui, por um lado, no alicerce para a segmentação de eventual estratégia logística na organização do fluxo de produtos do setor analisado e, por outro, num quadro conceitual de apoio à tomada de decisão no setor nas dimensões de responsabilidade, espaço e tempo.

Conforme os resultados gerados com base nas características do negócio e em suas relações com as decisões logísticas, a partir da análise das correlações significativas, conclui-se que a principal implicação gerencial deste trabalho é a possibilidade de orientar e direcionar o planejamento e a tomada de decisão no setor de máquinas e implementos agrícolas. Essa orientação e esse direcionamento poderão ser levados a efeito por meio da organização do fluxo de produtos, intensificando a busca por redução de custos e eficiência operacional, prevendo vendas e gerenciando os estoques de forma correta e com a maior assertividade possível.

Cabe salientar, finalmente, que esses fatos levantados pela avaliação transversal constituem-se num referencial teórico que poderá fundamentar futuros trabalhos de avaliação longitudinal no setor de máquinas e implementos agrícolas, os quais examinem, pela compreensão da evolução do fluxo de produtos, por que determinadas empresas conseguem desenvolver posições de vantagens competitivas e sustentá-las ao longo do tempo. 


\title{
The sector of machines and agricultural implements in state of Rio Grande do Sul: the determinants of logistics decisions
}

\begin{abstract}
With the goal to set up standards of logistic decisions, a research of field, exploratory and descriptive character was carried through, at an only moment, considering two categories of products, in different sizes of companies of machines and agricultural implements sector in the Northwestern Rio Grandense. For this, from a transversal evaluation of the logistic positioning, it was analyzed as the characteristics of the business influence in the logistic decisions in the types of organization of the flow of products. It could be verified that a homogeneous standard of logistic decisions in the sector does not exist, being this differentiated in relation to the size of companies. In the meantime to finish what is possible to guide and direct the planning and the taking of decision through the organization of the flow of products, which constitutes in a conceptual picture of support to the managers' taking of decision of the analyzed sector.
\end{abstract}

Key words: Standards of logistic decisions. Transversal evaluation. Organization of the flow of products. Sector of agricultural machines and implements.

\section{El sector de máquinas y implementos agrícolas en el estado del Río Grande del Sur: los determinantes de las decisiones logísticas}

\section{Resumen}

Con el fin de establecer normas para las decisiones de la logística, la llevamos a cabo una investigación de campo, exploratorio y descriptivo, en un solo momento, teniendo en cuenta dos categorías de productos en diferentes tamaños de empresas en el sector de la maquinaria e implementos agrícolas del Riograndense Noroeste. Para ello, de una evaluación transversal de la posición logística, se analiza como las características de la empresa afectan a las decisiones logísticas y los tipos de organización del flujo de producto. Se constató que no existe uma norma homogénea de las decisiones de logística en el sector, siendo esta diferencia en relación con el tamaño de las empresas. Sin embargo, parece que es posible orientar y dirigir la planificación y la tomada de decisiones mediante la organización del flujo de productos, lo que constituye un marco conceptual para apoyar la tomada de decisiones de los administradores en el análisis de la industria.

Palabras clave: Decisiones de la logística. La cruzada de análisis de la sección. La organización del flujo de productos. El sector de máquinas e implementos agrícolas. 


\section{Referências}

BALLOU, R. H. Business logistics management. Englewood Cliffs, NJ: Prentice Hall, 1992.

. Logística empresarial: transportes, administração de materiais e distribuição física. São Paulo: Atlas, 1993.

BANCO NACIONAL DE DESENVOLVIMENTO ECONÔMICO E SOCIAL (BNDES). Linha de financiamento. Disponível em: <http://www.bndes.gov.br>. Acesso em: 30 maio 2004.

CENTRO DE ESTUDOS EM LOGÍSTICA COPPEAD/UFRJ. Disponível em: <http://www.cel. coppead.ufrj.br>. Acesso em: 30 mar. 2004.

CHRISTOPHER, M. The agile supply chain: competing in volatile markets. Industrial Marketing Management, v. 29, p. 37-44, 2000.

. Logística e gerenciamento da cadeia de suprimento: estratégias para redução de custos e melhoria dos serviços. São Paulo: Pioneira. 2002.

FLEURY, P.F. Perspectivas para a logística brasileira. 1998. Disponível em: <http://www.cel.coppead.ufrj.br>. Acesso em: 10 jan. 2003.

GUJARATI, D. N. Econometria básica. 3. ed. São Paulo: Makron Books, 2000.

HOFFMANN, R. Estatística para economistas. 2. ed. rev. e ampl. São Paulo: Pioneira, 1991.

INSTITUTO BRASILEIRO DE GEOGRAFIA E ESTATÍSTICA(IBGE). Cartografia: mapeamento de unidades territoriais. 2004. Disponível em: <http://www.ibge.gov.br/cartografia/mapeamento unidades territoriais>. Acesso em: 30 maio 2004.

JAYARAMAN, V. Transportation, facility location an inventory issues in distribution network design. International Journal of Operations \& Production Management, v. 18, n. 5, p. 471-494, 1998.

LEEUW, S. D.; GOOR, A. R. The selection of distribution control techniques. The International Journal of Logistics Management, v. 10, n. 1, p. 97-112, 1999.

MENTZER, J.; KAHN, K.; BIENSTOCK, C. C. Sales forecasting executive study. London: Sage Publications, 1998.

PAGH, J. D.; COOPER, M. C. Supply chain postponement and speculation strategies: how to choose the rigth strategy. Journal of Business Logistics, v. 19, n. 2, p. 13-33, 1998.

PASQUAL, C. A. Características do negócio como determinantes do posicionamento logístico no setor de máquinas e implementos agrícolas da mesorregião Noroeste Rio-Grandense. 2005. Dissertação (Mestrado em Agronegócios) - Centro de Estudos e Pesquisa em Agronegócios, Universidade Federal do Rio Grande do Sul, Porto Alegre, 2005.

PORTER, M. E. Towards a dynamic theory of strategy. Strategic Management Journal, v. 12, p. 95-117, 1991.

ROMERO, B. The other side of supply management. Production and Inventory Management Journal, v. 32, n. 4, p. 1-4, 1991.

SARTORIS, A. Estatística e introdução à econometria. São Paulo: Saraiva, 2003.

SINDICATO DE MÁQUINAS AGRÍCOLAS DO ESTADO DO RIO GRANDE DO SUL (Simers). Disponível em: <http://www.simers.com.br>. Acesso em: 30 abr. 2004. 
WANKE, P. F. Posicionamento logístico de empresas brasileiras. 2001. Disponível em: <http:// www.cel.coppead.ufrj.br>. Acesso em: 12 dez. 2004.

Estratégia de posicionamento logístico: conceitos, implicações e análise da realidade brasileira. 2002. Disponível em: <http://www.cel.coppead.ufrj.br.> Acesso em: 02 dez. 2003.

O impacto das características do negócio nas decisões logísticas e na organização do fluxo de produtos: um estudo exploratório em seis setores econômicos. Revista de Administração Contemporânea - RAC, v. 7, n. 3, p. 163-180, jul./set. 2003a.

Organização do fluxo de produtos como base da estratégia logística de produtos acabados: uma síntese dos enfoques estático e dinâmico. 2003. 340 f. Tese (Doutorado em Engenharia de Produção) - Universidade Federal do Rio de Janeiro, Coppead/UFRJ, Rio de Janeiro, 2003b.

Gestão de estoques na cadeia de suprimento: decisões e modelos quantitativos. São Paulo: Atlas, 2003c. (Coleção Coppead de Administração).

WATERS, C. D. J. Inventory control and management. New York: John Wiley \& Sons, 1992. 